\title{
Racial disparities in drug court graduation rates: The role of recovery support groups and environments
}

John Robert Gallagher, PhD, LSW, LCAC Associate Professor, School of Social Work Indiana University South Bend (IUSB) (574) 514-1813

johngall@iupui.edu

Elizabeth A. Wahler, PhD

MSW Program Director/Assistant Professor, School of Social Work Indiana University Purdue University Indianapolis (IUPUI) (317) 274-6713

bwahler@iupui.edu

This is the author's manuscript of the article published in final edited form as:

Gallagher, J. R., \& Wahler, E. A. (2018). Racial Disparities in Drug Court Graduation Rates: The Role of Recovery Support Groups and Environments. Journal of Social Work Practice in the Addictions, 18(2), 113-127. https://doi.org/10.1080/1533256X.2018.1448277 


\section{Racial disparities in drug court graduation rates: The role of recovery support groups and environments}

There are over 3,000 drug courts in the United States, and research has demonstrated that, in some drug courts, African American participants are less likely to graduate than their white counterparts. Quantitative studies have documented the problem, but qualitative studies are needed to develop an in-depth understanding of this phenomenon through participants' experiences. This qualitative study asked African American participants $(n=31)$ about their lived experiences in drug court to develop insight into the factors that may contribute to racial disparities in drug court outcomes. African Americans had favorable views toward both mandated and natural recovery support groups, and they felt that participating in these support groups increased their likelihood of graduating drug court. Conversely, African Americans felt that a barrier to graduating drug court was their environments, mainly risk factors posed by family, neighborhoods, and peers. Implications for drug court practice are discussed.

Keywords: African American, criminal recidivism, drug court, graduation rates, racial disparities, substance use disorder 


\section{Introduction}

In 2016, the Surgeon General of the United States released a report which provided an overview on addiction in America, including the prevalence of substance use disorders and cooccurring mental illnesses, the culture of and barriers to accessing treatment, the negative consequences of drug misuse, the neurological impact of addiction, and future plans to promote recovery within our communities (U.S. Department of Health and Human Services (HHS), Office of the Surgeon General, 2016). The report offers valuable insight into addiction in America. Of the many notable findings, the findings related to the financial impact of addiction are alarming. It is estimated that the yearly economic impact of substance misuse and substance use disorders, alcohol and illicit drug use combined, is $\$ 442$ billion dollars. This cost is as a result of the many consequences associated with addiction, such as intimate partner violence, unintended pregnancies, the spread of infectious diseases, healthcare, and, relevant to the current study, the high rate of crime and arrests associated with individuals who have a substance use disorder. As a result, the criminal justice system is one avenue in treating substance use disorders, although certainly not the ideal avenue. However, when only $14 \%$ of individuals who have a substance use disorder actually receive treatment, it is not surprising that many eventually get arrested (Center for Behavioral Health Statistics and Quality, 2016). One of the ways that the criminal justice system has responded to this problem is through the development of drug courts.

Drug courts have been in an important part of the criminal justice system since the first

program began in 1989 in Dade County (Miami), Florida. In nearly three decades, the number of drug courts has increased to 3,057 and these programs are now operating in all 50 United States (National Association of Drug Court Professionals [NADCP], 2017). Drug courts are a unique criminal justice intervention that focus on rehabilitation for individuals who have a substance use disorder, while also balancing public safety. Drug courts are conceptualized by their 10 key 
components, which are designed to enhance motivation for change through a strengths-based, non-adversarial approach (NADCP, 2004). Key components of drug courts, for example, include requiring participants to attend treatment for their substance use disorders, having participants meet with the judge frequently, sometimes weekly, to provide an update on their progress in the program, offering incentives (e.g. round of applause in court) and sanctions (e.g. community service) in response to participants' behaviors in the program, and having frequent and random drug testing.

Drug courts continue to expand because, simply put, they are effective. Drug courts are perhaps the most evaluated criminal justice program ever, and while there are a few studies suggesting that drug court is equally as effective at reducing criminal recidivism as other interventions, such as probation, these studies are not the norm (Bavon, 2001; Listwan, Sundt, Holsinger, \& Latessa, 2003; Wolfe, Guydish, \& Termondt, 2002). The majority of studies have shown that drug court participants are less likely to recidivate than comparison groups, and recent meta-analyses have supported this evidence (Mitchell, Wilson, Eggers, \& MacKenzie, 2012; Shaffer, 2011).

The evidence supporting drug court as an effective intervention continues to grow, but at the same time, some studies have found that drug courts may not be as effective for African American participants as it is for white participants (Marlowe, 2013; McKean \& WarrenGordon, 2011). Gallagher (2013a), for example, found in a Texas drug court that white participants graduated the program at $65 \%$, whereas the graduate rate for African Americans was only 46\%. Furthermore, Dannerbeck, Harris, Sundet, and Lloyd (2006) found that 55\% of white participants and only $28 \%$ of African American participants graduated from drug courts in Missouri. While racial disparities in graduation rates are not found in every program, a pattern 
has emerged, and this warranted a response from the nation's leading association on drug court practice. The NADCP Board of Directors (2010) released a statement titled The Equivalent Treatment of Racial and Ethnic Minority Participants in Drug Courts. In the statement, drug courts were charged with evaluating their programs to assess whether or not racial disparities existed in graduation rates, and if so, develop strategies to rectify the problem.

The concern, however, is that strategies to rectify racial disparities in graduation rates are unknown, or at best anecdotal, because little is known about how participants view the program. The majority of drug court research is quantitative. Therefore, the benefits of qualitative research are not fully seen in the literature, and qualitative research is needed to develop an indepth understanding of drug court from the lived experiences of African Americans. To date, there are two known studies that have explored this phenomenon. Gallagher (2013b) interviewed 14 African American participants and offered a variety of hypotheses as to why racial disparities exist in graduation outcomes, such as African Americans' beliefs that they were not receiving individualized treatment, the format of Alcoholics Anonymous (AA) and Narcotics Anonymous (NA) being inconsistent with their culture, and beliefs that sanctions were delivered in culturally insensitive manners. Specifically, in regards to individualized treatment, African Americans felt that the drug court did not get to know their histories and some of the unique circumstances that may have impacted their performance in the program. AA and NA were described as inconsistent with their culture because they did not prefer to discuss their personal problems in a public setting. Rather, they viewed family, for example, as a more effective support system, and relying on their families for support was described as a cultural norm. African Americans also felt that they were treated differently than their white and Hispanic counterparts when receiving a sanction from the judge, and actually offered examples of the 
court audience and drug court staff laughing during their sanctions (Gallagher, 2013b). In a recent qualitative study, Gallagher and Nordberg (2016) compared and contrasted the lived experiences of white $(n=22)$ and African American $(n=16)$ participants in a Midwestern drug court. They found that African Americans were dissatisfied with the quality of treatment they received for their substance use disorders, a potential factor as to why African Americans graduate drug court less often than their white counterparts.

In conclusion, little is known about reasons racial disparities often exist in drug court outcomes despite a call for effective strategies for reducing racial disparities. Thus, this qualitative study contributes to the drug court literature by being one of only three known studies exploring factors that may contribute to racial disparities in drug court graduation rates. This was accomplished by giving African American participants a voice about their experiences in drug court. This study also is the largest known study to explore this phenomenon, with a sample of 31 .

\section{Methodology}

The research question for this study is: What are African American participants' views on the most helpful aspects of drug court and how drug court could be more helpful in supporting them in graduating the program? This research commenced with approval from an Institutional Review Board (IRB). Research participants were recruited from a drug court located in a Midwestern state. In 2016, the first author attended a drug court hearing where he introduced himself to the participants, described the research, and invited them to complete the Drug Court Participant Satisfaction Survey. The satisfaction survey was developed by the researchers and included brief demographic information and open-ended questions. Specifically, participants were asked their age, gender, race and ethnicity, and how long they had been in the 
drug court. Then, participants answered the following two open-ended questions. First, "could you please describe what aspects of drug court are most helpful to you in supporting you in graduating the program?" Second, "could you please describe how drug court could be more helpful to you in supporting you in graduating the program?" Participants were provided with a pen and the satisfaction survey, and a private location for them to answer the questions. No incentive was provided by the researchers for participating in this study.

A narrative analysis of the answers provided on the satisfaction surveys was completed. Narrative analysis was an effective approach to answer the research question for this study, as the goal was to provide participants with an anonymous environment to freely express their experiences in drug court (Padgett, 2008). Narrative analysis is also designed to capture the behind-the-scenes aspects of participants and their role in a particular program, such as drug court (Padgett, 2008). This data analysis was also guided by phenomenology. According to Padgett (2008), phenomenology is recommended when you have a research sample with similar characteristics, such as being African American and a member of drug court, and when research questions can be answered best through participants' sharing their own personal livedexperiences with a particular phenomenon.

The data were transcribed verbatim and uploaded to NVivo 10 for analysis. The data analysis followed a three-step process, as suggested by Miles and Huberman (1994) and Padgett (2008). First, consistent with narrative analysis, and to promote immersion in the data, the researchers read all of the data on five occasions during a two-week period. During this process, a phenomenological approach was utilized by paying particular attention to examples of participants' lived experiences in the drug court. Second, data focused on participants' lived experiences within the context of drug court were extracted and grouped together. Third, the 
grouped data were reviewed to assess for consistent responses from participants. Grouped data that did not demonstrate consistent responses were considered outliers and utilized for negative cases analyses. Grouped data that did demonstrate consistent responses were identified as themes; themes were summarized and conceptualized by extracting direct quotes from participants' satisfaction surveys.

Last, several strategies were used to increase the rigor and validity of the qualitative findings. First, observer triangulation and interdisciplinary triangulation were used (Padgett, 2008). Observer triangulation was used to offer more than one perspective on interpreting the data, with the goal of increasing the objectivity of the findings. Interdisciplinary triangulation was accomplished by having professionals from three disciplines, social work, psychology, and criminal justice, collaborate on the data analysis and findings, which again offers another method to increase the objectivity of the findings and reduce researcher bias. Second, peer debriefing and support was used to assist the researchers in bracketing preconceived thoughts about the phenomenon being evaluated, which is an essential part of phenomenological analysis (Padgett, 2008). This was accomplished through frequent consultation, at least weekly, with colleagues who have expertise in qualitative research and were not directly involved in this study. The consultations involved offering colleagues portions of the data analysis to assess the logic of the themes developed. Third, negative case analysis was used to explore personal biases that the researchers may have had and to present a balanced, fair interpretation of the data (Padgett, 2008). The negative cases are presented in the findings section following each theme.

\section{Findings}

The response rate was $100 \%$. Thirty-one participants were recruited and all completed a Drug Court Participant Satisfaction Survey. The ages of the participants ranged from 18 to 42 
years old. The average age was 26 years old. In regards to gender, $74 \%(n=23)$ were male and $26 \%(\mathrm{n}=8)$ were female. All participants $(\mathrm{n}=31 ; 100 \%)$ self-identified as African American. Participants' length in the program ranged from approximately 1 month to 16 months, and the average length in the program was approximately 8 months. Throughout the analysis, a number of major thoughts and experiences were shared consistently by participants of the drug court. Two themes emerged from the data.

\section{Mandated and Natural Recovery Support Groups}

The first theme to emerge from the data was Mandated and Natural Recovery Support Groups. Twenty-three (74\%) of the 31 participants shared experiences that contributed to this theme. Recovery support groups were identified as the most helpful aspect of drug court that supported participants in graduating the program. Participants gave examples of both mandated and natural recovery support groups. As conceptualized in the below quotes, mandated recovery support groups were ones that participants were court-ordered to attend, which included self-help meetings such as Alcoholics Anonymous (AA) and Narcotics Anonymous (NA). Natural recovery support groups were resources participants already had in their lives that they utilized frequently to help maintain their recovery, such as members of their churches, their priests and pastors, coworkers, and hobbies they enjoy, for example. A male participant describes his experience with a mandated support group. He states:

The AA meetings are an excellent way to make great decisions in life and should be kept. AA meetings are helping me graduate and have given me a clear look at my addiction and how to think differently. At first, I was hesitant to go to AA because I didn't like being court-ordered to them, but after you attend a few, you realize the people really care and they want to support you. 
A female participant shared a similar experience, where she was resistant to attending NA at the beginning of drug court, but eventually she grew to find the meetings as a valuable resource. She described the experience as:

I feel the weekly meetings are extremely helpful. I hated them at first and told my case manager I didn't want to go, but I went anyways so I didn't get in trouble. Now, I like them. Sometimes sitting, listening, and interacting with others who have seen the ups and downs of the life you are heading towards can really be an eye opening experience. To see people older than you in such a vulnerable manner is a truly humbling experience. Hearing the horrific, sometimes tragic stories, of drug abuse and drug addiction really forced me to think, is this where I want to be in 10 years? I knew it wasn't. Before going to the weekly meetings I never gave serious thought to stop using. Now, through the help and guidance of my peers and mentors I meet at weekly NA meetings, I have been able to stay clean without having any thought of using again.

A final example of a mandated recovery support group is from a male participant who highlights the camaraderie that he experiences when he attends both AA and NA meetings, and he feels this camaraderie will help him be successful in drug court. $\mathrm{He}$ shares:

The meetings are the most helpful. I go to both AA and NA and more than the court is making me attend. I enjoy the people there, they really understand you, and they understand what I am going through. It's just nice to be around people who support you no matter what. They don't judge you or think of you as a bad man or poor father. I like the drug court, the staff and judge are really nice, but 
the most helpful aspect of the program are the people I see at my meetings. They are my recovery support group.

The next participant distinguishes between mandated and natural recovery support groups. He feels that both are supportive of his recovery, but he tends to value his natural recovery support groups more so than mandated ones. He notes:

The court makes you attend AA or NA meetings and we have to go or we get sanctioned. I don't mind going, but sometimes I wish the judge would count the natural supports I have in my life as fulfilling the requirements of the program, but she doesn't. I attend church each week and talk with my pastor weekly, as well, sometimes several times a week. This is where I get my support. This is what will help me graduate drug court. My suggestion is to continue making us attend AA and NA meetings, but also acknowledge that there are many other things than AA and NA meetings that support my recovery, like going to church, singing in my choir, or having breakfast with friends.

A female participant describes a natural recovery support group, one that may not be seen as a norm, but as she highlights, she feels it helps her maintain abstinence from illicit drugs and supports her participation in drug court. She shares:

When I was getting high, I didn't care about how I looked. I was a mess, sometimes didn't shower for a few days and never did my hair and nails. Once I got clean, I started taking care of myself better. Every week I get my hair and nails done and when I leave there I feel great! My beautician is like my counselor; she hears all my problems and gives me advice. She is a major part of my recovery, and she knows I am in drug court and all the challenges I face. The 
court makes us go to NA meetings each week, but I find getting my hair and nails done is much more helpful. NA meetings can't make me feel beautiful, and when I feel beautiful, I am less likely to relapse and more likely to complete drug court. A final example of a natural recovery support group comes from a male participant who has played basketball since his youth. He states:

I am now doing behaviors that help me stop smoking. In the past, I would run the streets selling drugs and smoking weed and getting into all types of trouble.

When I got to drug court and realized that I had to stop smoking weed, I decided to join a basketball league. I have played basketball since a kid and was good in high school. Each week, I have at least one game and practice and that helps me stay sober. I know it's not part of the drug court program, but playing basketball is what helps me do well in this court.

Overall, when participants were asked about the most helpful aspects of the drug court that supported them in graduating the program, they identified two types of recovery support groups. Mandated recovery support groups were defined as those that they were court-ordered to attend, and if they did not, a negative consequence may be imposed by the judge. Although court-ordered, participants shared favorable views towards AA and NA meetings and shared concrete examples on how participation in these meetings helped them do well in drug court. Interestingly, participants also shared that natural recovery support groups, which are not an official part of the drug court programming, were equally as helpful in supporting them in graduating the program. It was promising to see that both types of recovery support groups were viewed favorably. 
The negative case analysis revealed 5 of the 31 participants (16\%) shared experiences that differed from that of the theme. All five examples were related to mandated recovery support groups. One participant, for example, commented, “I don't like going to the 12 -step meetings. I have better things to do than hear people talk about drug and alcohol. I leave the meetings triggered because of all the drug talk. It makes me want to get high." Another participant shared, "They expect too much from us. I stopped using drugs on my own and I don't have time to go to AA and NA meetings each week. I don't need them. They are a waste of my time." A final example is from a participant who felt that she would benefit more from receiving resources to gain employment, as compared to being court-ordered to attend recovery support groups. Specifically, she notes:

It could be more helpful for me to not have so many of those support group meetings each week. I'd benefit more from a program that helped recovering addicts find jobs and help them get back their licenses so they can get to and from work. Working and paying the bills is what motivates me to stay clean, not sitting through meetings and hearing people's problems.

\section{Environment as a Barrier to Success}

The second theme to emerge from the data was Environment as a Barrier to Success. Twenty (65\%) of the 31 participants shared experiences that contributed to this theme. When asked to describe how the drug court could be more helpful in supporting participants in graduating, they actually referred their environments, as compared to a specific component of the drug court. Participants, for instance, offered examples on how their family environments, neighborhoods, and network of peers included noticeable risk factors that were not conducive to their goals in drug court, which were to graduate 
and not recidivate. A male participant offers an example of how his environment was a barrier to his success in drug court. He shares:

The drug court does a good job in helping us graduate. I really believe that want us to do well and be successful people. The problem is our environments. We can learn all we want about recovery and not being criminals, but when we leave court, the moment we leave court, we go right back to what we know, smoking weed and selling drugs and trying to stay alive. I have already got in trouble in the program for a positive drop [urine drug screen] and that's because all my friends get high, and when I am around them, I get high. If I don't graduate this program, it's because my environment won't let me change.

Another male participant describes how his family environment is a risk factor for him. He notes:

I need help with family. My entire family uses drugs and has been in-and-out of jail at some point in their lives. It's hard to be in court and have the judge and all the other people really supportive, then go home to drugs. I relapsed because it's hard not to use drugs when everyone in my house is smoking and drinking. I am not sure what to do. Maybe the drug court could make families get treatment, too, but I know my family would not be down for that. I want to graduate, but I don't think I will.

A female participant contemplates making changes to her network of friends because she does not feel she will be able to graduate drug court if she maintains the relationships. She candidly processes how this is a challenge for her. Specifically, she shares: 
At the NA meetings, they talk about changing people, places, and things. If I want to graduate drug court, I need to change them all, especially the people. This is not easy. My friends are my life. They have been with me through the good and bad times, when I graduated high school and when the not so good times like when I got arrested. They still use drugs and try and stay away from the police, but they always seem to find us. At times, I feel like just saying give me my jail time so I can get it over with and be with my friends. Other times, I do want to change my life. Drug court could help me by helping me figure out how to still have my friends, but also do good in the program. I do not think that I will discuss this with them because I know what they will say, change people, places, and things.

A male participant shared that he is fearful for his safety, and as a result, he continues to carry a gun with him at times although he knows it is illegal. He offers insight into the challenges of meeting the needs of drug court while also protecting himself in a community that he sees as unsafe. He states:

I want to graduate drug court and get out of this city. I have lived many places and this is the most dangerous city of all. If I don't carry my piece [gun] with me, I will get robbed, killed, or assaulted. I understand it is illegal for me to have a gun, but I'd rather the court put me in jail then die. I am safer in jail, my people are there. I am trying really hard to change, but the drug court doesn't get it. They want us to be perfect and that is never going to happen. I can't talk with my case manager or judge about it, they don't get it, and they may sanction me or arrest me. 
Overall, when participants were asked about how the drug court could be more helpful in supporting them in graduating the program, they, interestingly, did not identify a specific aspect of drug court. Rather, they discussed how their environments were a barrier to being successful in drug court, and some felt that they could not discuss these barriers with the drug court team, as some of the behaviors, such as carrying a gun, were illegal, or being around friends who are using drugs, is noncompliant with drug court rules. Based on these findings, it appears that for the majority of drug court participants, a barrier to graduating the program was that their family environments, neighborhoods, and/or networks of peers posed risk factors that increased their likelihood of criminality and relapse.

The negative case analysis revealed 4 of the 31 participants (13\%) shared experiences that differed from that of the theme. All four examples described how their family environments supported their recovery and increased their likelihood of graduating drug court. One participant, for example, commented, "The drug court does a good job helping me and my family. My family gets healthier as I stop smoking." Another participant shared, "My biggest support is not the drug court, it is my family. My husband and kids are always by my side and have my back. They are proud of me and that keeps me going in a positive direction." In the final example, a participant describes how the support she received from her family actually prevented her from a relapse. Specifically, she shares:

I will graduate for my mom and dad, my son, and everyone who supports me. I actually found that our family has gotten closer since I have been in drug court and that is a good feeling. I was in one of those situations once where I could 
have smoked weed, but chose not to because I thought of how that would hurt my family and disappoint them so I did not use. My family is what helps me do well in drug court.

\section{Discussion}

Results from this study of African American drug court participants provided insight into the factors that may contribute to racial disparities in drug court outcomes. Notably, the majority of African American participants in this sample had favorable views toward both mandated and natural recovery support groups, and they felt that participating in these support groups increased their likelihood of graduating drug court. This finding contrasts with results from previous research on the topic (Gallagher, 2013b). That sample, from Texas, disclosed that they felt AA, NA, and other recovery support groups were not helpful or consistent with their cultural values and beliefs. Rather, they viewed their families as their primary, and most helpful, support systems, and utilizing family seemed to be their cultural norm. These conflicting findings demonstrate the need for more research on this topic, but also highlight that African American drug court participants are not a homogenous group and should not be treated as such when devising recovery or treatment plans. Sanders and Powell (2012) also highlight the importance of offering multiple options for recovery or treatment plans for African Americans, options that can be incorporated into drug court programming, such as supporting participants who chose to engage in spiritual and religious practices as part of their treatment.

Similarly, participants in this study discussed the positive influence of natural supports on their recovery and drug court participation rather than only formal supports directly related to substance use like AA and NA. In some cases, participants indicated that these natural supports had a bigger influence on their experiences in drug court than formal recovery supports. These 
findings are consistent with previous research on general populations of recovering individuals that have found there are many paths to recovery from drug and alcohol abuse or dependence, including general social support, faith-based groups, and other natural supports appearing to be unrelated to alcohol and drug use directly (White \& Kurtz, 2006). Similarly, other research examining the recovery process of African Americans found that participants described various ways of seeking support and moving towards addiction recovery; these included faith-based supports, health-related programs, advocacy activities, and educational/personal enrichment programs (Sanders \& Powell, 2012). In the current study, our participants discussed paths to recovery that included sports and physical activity, beauty regimens, worship and other faithbased support, and positive family members. These findings as well as the extant literature indicate that it is essential for drug courts to systematically assess and incorporate natural supports into participants' lives when developing recovery plans and recommendations. This has implications for drug courts and suggests that African American participants could benefit from having tailored recovery plans that fit the individual as much as possible and recognize multiple forms of support. A growing body of literature purports the benefits of personalized treatment planning for many different populations experiencing substance use disorders (Litten et al., 2015; Marsden, et al., 2014; Woody, 2014), and further justifies the use of individualized plans for African American drug court participants in recognition of their heterogeneity.

Also notable from this study is the frequency with which African American participants in this sample reported that their environments were a barrier to graduating drug court. This supports a social ecological theoretical perspective of substance use and recovery, which has also been applied to substance use in other populations such as Asian-Americans (Hong, Huang, Sabri, \& Kim, 2011) and Latino-Americans (Parsai, Marsiglia, \& Kulis, 2010). Participants in 
the current sample reported living in environments that contained relapse and recidivism risk factors posed by family, neighborhoods, and peers. Since this study recruited participants from a crime-ridden and high-poverty urban area, these findings are most likely a result of the socioeconomic status of the area rather than specific to the racial identification of the participants. Notably, the criminal justice system as a whole operates based on personal accountability and responsibility, yet addiction is complicated and based on myriad factors including social and environmental influences. Social ecological theories of addiction indicate that substance use is partially related to an individual person's characteristics, but is also directly related to the context and environment in which the person lives (Gruenewald, Remer, \& LaScala, 2014). For example, safe and stable housing is essential for addiction recovery, abstinence from illicit substances, and preventing recidivism (Boardman, Finch, Ellison, Williams, \& Jackson, 2001; Petersilia, 2003). Yet, low-income individuals often have few housing options and may be forced to live in unsafe neighborhoods or with family members or friends who might be using substances. Additionally, unsafe neighborhoods and environments result in increased stress, which also increases the likelihood of relapse (Boardman et al., 2001). Poverty and economic hardship have been found in multiple other studies to predict substance use and relapse (Buka, 2002), particularly in the criminal justice population (Wahler, 2015), and increased stress for people attempting to recovery from substance use disorders (Cole, Logan, \& Walker, 2011). Poverty is also often predictive of crime and recidivism (Brown \& Males, 2011; Moore \& Elkavich, 2008). Thus, drug court professionals working with low-income African American clients should consider how their program can address some of these social and environmental factors to reduce participants' stress and prevent relapse and recidivism. 


\section{Implications for Practice}

The findings from this study have implications for social workers and other drug court professionals. First, multiple types of support should be considered for African American participants. Although many participants might benefit from organized recovery-support groups such as AA or NA, other participants might find more support from other services or activities. In fact, based on previous research in the field (Gallagher, 2013b) and the results from some of the participants in the current study, AA or NA might not be beneficial to at least some African American participants. Although difficult to monitor in a court-based environment, individual recovery plans should be developed as much as possible to enable participants to pursue a path to recovery that suits them. Sanders and Powell (2012) recommend educating clients on the multiple ways of reaching recovery in the African American community and allow clients to determine their own path. Faith-based programs, educational and personal enrichment activities, or other types of supports should be considered and discussed with participants as viable options for obtaining positive support.

Additionally, courts should take a social-ecological approach when assessing and working with their participants. Although the criminal justice system tends to operate based on personal responsibility and accountability, environmental factors impact the recovery process significantly, particularly with low-income individuals. Social workers and drug court professionals should address environmental factors when possible. Assistance with obtaining and maintaining employment, meeting basic needs (housing, food, medical care, etc.), furthering educational level, or otherwise addressing long-term stability and economic mobility could aid in drug court completion rates, prevent recidivism, and encourage long-term recovery. 


\section{Limitations}

The findings from this study are not generalizable beyond the research sample. While the findings can be used to guide future research and support other drug courts in developing qualitative methods in evaluating their programs, the findings are specific to the African Americans evaluated in this study. Next, data were collected through a satisfaction survey. This approach offered participants an opportunity to share their lived experiences in drug court. However, the use of individual interviews or focus groups would have allowed the researchers to ask probing questions, which may have provided more data and additional themes. Last, member checking, or going back to the research participants to consult with them about the data analysis and confirm the development of themes, was not possible for this study. When feasible, it is recommended that future qualitative research incorporate member checking into the methodology to increase the rigor of the data analysis and provide research participants additional insight into the study. 


\section{References}

Bavon, A. (2001). The effect of the Tarrant county drug court program on recidivism. Evaluation and Program Planning, 24, 13-22.

Boardman, J. D., Finch, B. K., Ellison, C., Williams, D., \& Jackson, J. (2001). Neighborhood disadvantage, stress, and drug use among adults. Journal of Health and Social Behavior 42(2), 151-165.

Brown, E., \& Males, M. (2011). Does age or poverty level best predict criminal arrest and homicide rates? A preliminary investigation. Justice Policy Journal, 8(1), 2-30.

Buka, S. L. (2002). Disparities in health status and substance use: Ethnicity and socioeconomic factors. Public Health Reports, 117(S1), S118-S125.

Center for Behavioral Health Statistics and Quality. (2016). Key substance use and mental health indicators in the United States: Results from the 2015 National Survey on Drug Use and Health (HHS Publication No. SMA 16-4984, NSDUH Series H-51). Retrieved from http://www.samhsa.gov/data/

Cole, J., Logan, T. K., \& Walker, R. (2011). Social exclusion, personal control, self-regulation, and stress among substance abuse treatment clients. Drug and Alcohol Dependence, 113(1), 13-20.

Dannerbeck, A., Harris, G., Sundet, P., \& Lloyd, K. (2006). Understanding and responding to racial differences in drug court outcomes. Journal of Ethnicity in Substance Abuse, 5(2), $1-22$.

Gallagher, J. R. (2013a). Drug court graduation rates: Implications for policy advocacy and future research. Alcoholism Treatment Quarterly, 31, 241-253. 
Gallagher, J. R. (2013b). African American participants' views on racial disparities in drug court outcomes. Journal of Social Work Practice in the Addictions, 13, 143-162.

Gallagher, J. R., \& Nordberg, A. (2016). Comparing and contrasting white and African American participants' lived experiences in drug court. Journal of Ethnicity in Criminal Justice, 14(2), 100-119.

Gruenewald, P. J., Remer, L. G., \& LaScala, E. A. (2014). Testing a social ecological model of alcohol use: The California 50-city study. Addiction, 109(5), 736-745.

Hong, J. S., Huang, H., Sabri, B., \& Kim, J. S. (2011). Substance abuse among Asian American youth: An ecological review of the literature. Children and Youth Services Review, $33(5), 669-677$.

Listwan, S. J., Sundt, J. L., Holsinger, A. M., \& Latessa, E. J. (2003). The effect of drug court programming on recidivism: The Cincinnati experience. Crime \& Delinquency, 49, 389-411.

Litten, R. Z., Ryan, R. L., Falk, D. E., Reilly, M., Fertig, J. B., \& Koob, G. F. (2015). Heterogeneity of alcohol use disorder: Understanding mechanisms to advance personalized treatment. Alcoholism: Clinical \& Experimental Research, 39(4), 579-584. Marlowe, D. B. (2013). Achieving racial and ethnic fairness in drug courts. Court Review, 49, 40-47.

Marsden, J., Eastwood, B., Ali, R., Burkinshaw, P., Chohan, G., Copello, A.,...Day, E. (2014). Development of the Addiction Dimensions for Assessment and Personalized Treatment (ADAPT). Drug and Alcohol Dependence, 139(1), 121-131. 
McKean, J., \& Warren-Gordon, K. (2011). Racial differences in graduation rates from adult drug treatment courts. Journal of Ethnicity in Criminal Justice, 9, 41-55.

Miles, M. B., \& Huberman, A. M. (1994). An expanded sourcebook: Qualitative data analysis (2nd ed.). Thousand Oaks, CA: Sage.

Mitchell, O., Wilson, D. B., Eggers, A., \& MacKenzie, D. L. (2012). Assessing the effectiveness of drug courts on recidivism: A meta-analytic review of traditional and non-traditional drug courts. Journal of Criminal Justice, 40, 60-71.

Moore, L. D., \& Elkavich, A. (2008). Who's using and who's doing time: Incarceration, the war on drugs, and public health. American Journal of Public Health, 98(5), 782-786.

National Association of Drug Court Professionals. (2004). Defining drug courts: The key components. Retrieved from https://www.ncjrs.gov/pdffiles1/bja/205621.pdf

National Association of Drug Court Professionals. (2017). About NADCP. Retrieved from http://www.nadcp.org/learn/about-nadcp

National Association of Drug Court Professionals Board of Directors. (2010). The equivalent Treatment of racial and ethnic minority participants in drug courts. Retrieved from http://nadcp.org/sites/default/files/nadcp/NADCP\%20Board\%20Resolution\%20\%20The $\% 20$ Equivalent $\% 20$ Treatment $\% 20$ of $\% 20$ Racial $\% 20$ and $\% 20$ Ethnic $\% 20$ Minority \%20Participants\%20in\%20Drug\%20Courts\%2006-01-10.pdf

Padgett, D. K. (2008). Qualitative methods in social work research (2nd ed.). Thousand Oaks, CA: Sage.

Parsai, M., Marsiglia, F. F., \& Kulis, S. (2010). Parental monitoring, religious involvement, and drug use among Latino and non-Latino youth in the Southwestern United States. British Journal of Social Work, 40(1), 100-114. 
Petersilia, J. C. (2003). When prisoners come home: Parole and prisoner reentry. Oxford: Oxford University Press.

Sanders, M., \& Powell, J. (2012). Multiple pathways of recovery for African American men. Alcoholism Treatment Quarterly, 30, 315-325.

Shaffer, D. K. (2011). Looking inside the black box of drug courts: A meta-analytic review. Justice Quarterly, 28, 493-521.

U.S. Department of Health and Human Services (HHS), Office of the Surgeon General. (2016). Facing addiction in America: The surgeon general's report on alcohol, drugs, and health. Washington, DC: HHS.

Wahler, E. A. (2015). Social disadvantage and economic hardship as predictors of follow-up addiction severity after substance abuse treatment: Does referral to treatment by the criminal justice system matter? Alcoholism Treatment Quarterly, 33(1), 6-27.

White, W. \& Kurtz, E. (2006). The varieties of recovery experience. International Journal of Self Help and Self Care, 3(1), 21-61.

Wolfe, E., Guydish, J., \& Termondt, J. (2002). A drug court outcome evaluation comparing arrests in a two year follow-up period. Journal of Drug Issues, 32, 1155-1171.

Woody, G. E. (2014). Progress in addiction treatment: From one-size-fits-all to medications and treatment matching. Substance Abuse, 35(2), 110-113. 